\title{
I solation and prevalence of Salmonella from chicken meat and cattle milk collected from local markets of Patna, I ndia
}

\author{
Purushottam Kaushik ${ }^{1}$, Anjay $^{1}$, Savita Kumari ${ }^{2}$, Sanjay Kumar Bharti ${ }^{3}$ and Shanker Dayal ${ }^{4}$ \\ 1. Department of Veterinary Public Health, Bihar Veterinary College, Patna, Bihar, India; \\ 2. Department of Veterinary Microbiology, Bihar Veterinary College, Patna, Bihar, India; \\ 3. Department of Veterinary Anatomy, Bihar Veterinary College, Patna, Bihar, India: \\ 4. Indian Council of Agricultural Research- Regional centre for Eastern region, Patna, Bihar, India \\ Corresponding author: Purushottam Kaushik, email: drkaushikvet@rediffmail.com \\ Received: 05-11-2013, Revised: 27-12-2013, Accepted: 02-01-2014, Published online: 11-02-2014
}

doi: $10.14202 /$ vetworld.2014.62-65

How to cite this article: Kaushik P, Anjay, Kumari S, Bharti SK and Dayal S (2014) I solation and prevalence of Salmonella from chicken meat and cattle milk collected from local markets of Patna, India, Veterinary World 7(2): 62-65.

\begin{abstract}
Aim: To evaluate the hygienic quality of raw chicken meat and raw milk sold in the local markets of Patna with reference to isolation of Salmonella and antibiotic resistance pattern of Salmonella against commonly used antibiotics.
\end{abstract}

Materials and Methods: A total of 370 samples comprising of 228 chicken meat and 142 market milk samples were processed for isolation and serotyping, supplemented with molecular detection of isolates targeting invA gene of Salmonella. All the isolates were tested against commonly used antibiotics (13 nos).

Results: Out of 370 samples, $23.7 \%$ (54/228) chicken meat and 7.7\% (11/142) milk samples were found positive for Salmonella based on biochemical reactions. The serotyping of Salmonella isolates showed an incidence of $6.1 \%$ of Salmonella typhimurium, $2.6 \%$ of $S$. newport, $1.7 \%$ of $S$. gallinarum and $0.4 \%$ each of $S$. enteritidis, S. infantis and $S$. worthington in chicken meat; and $2.1 \%$ of S. typhimurium and $1.4 \%$ of $S$. newport in market milk samples. Polymerase chain reaction targeting invA gene showed positive presence of Salmonella in 18.42\% chicken meat and 5.6\% market milk samples.

Conclusion: The antibiotic susceptibility test revealed the presence of multiple drug resistant Salmonella in chicken meat and milk. The present study indicates high prevalence of Salmonella in raw chicken meat and milk due to poor hygienic practices and therefore emphasizes the need for adopting these hygienic practices.

Keywords: antibiotic resistance, invA, Salmonella, serotypes.

\section{Introduction}

Salmonella enterica is a leading cause of enteric diseases in humans and animals with millions of illness reported worldwide. The nontyphoidal Salmonella serovars are predominantly associated with food of animal origin such as eggs, milk, poultry, beef and pork meat responsible for zoonotic transmission $[1,2]$. The incidence of salmonellosis has been reported in many developing countries including India, Egypt, Brazil and Zimbabwe [3]. S. enterica serovar Typhimurium and $S$. enterica serovar Enteritidis are the most frequently encountered species from foods like poultry, pork and beef products [4]. Incidence of Salmonella in chicken meat and milk has been reported by several workers using different methods and the frequency of detection ranges from $6.79 \%$ to $97.6 \%$ [5] in chicken meat and $0.17 \%$ to $28.6 \%$ [6] in raw milk. Although, isolation of Salmonella by growth in a culture medium followed by serotyping is considered as the gold standard for confirmation of Salmonella, it is also time consuming and labour intensive.

Therefore techniques like PCR are increasingly being used for rapid detection and confirmation of

Copyright: The authors. This article is an open access article licensed under the terms of the Creative Commons Attribution License (http://creativecommons.org/licenses/by/2.0) which permits unrestricted use, distribution and reproduction in any medium, provided the work is properly cited.
Salmonella [7]. Amplification of invA gene of Salmonella has been reported as a suitable target for PCR amplification, with potential diagnostic applications [8]. Emergence of multidrug-resistant $S$. enterica serovars has been increasing and has become a major health concern [1]. One of the contributing factors for the widespread dissemination of multi drug resistant bacteria has been the indiscriminate prophylactic and therapeutic use of antimicrobial agents in food animals [9].

Therefore the present study was aimed to study the prevalence of Salmonella and also characterize the distribution of the drug resistant pathogen in chicken meat and market milk of Patna, India.

\section{Materials and Methods}

Sample collection: A simple random method was adopted to collect a total of 370 samples constituting fresh chicken meat $(n=228)$ and milk $(n=142)$ from different vendors of Patna, Bihar between September, 2010 to March, 2013. The samples were maintained on ice, transported to the laboratory and processed within $1 \mathrm{hr}$ of collection.

I solation and biochemical characterization: Ten grams of chicken meat and $0.5 \mathrm{ml}$ of milk samples were used for pre-enrichment in buffered peptone water (BPW), at $37^{\circ} \mathrm{C}$ for $18 \mathrm{hrs}$. One $\mathrm{ml}$ of pre-enriched broth was transferred into Selenite Cystine broth and 
Table-1. Incidence and relative occurrence of Salmonella serovars in chicken meat and milk

\begin{tabular}{lccccc}
\hline Serotype & \multicolumn{2}{c}{ Chicken meat } & & \multicolumn{2}{c}{ Market milk } \\
\cline { 2 - 3 } \cline { 5 - 6 } & Number isolated & Relative occurrence (\%) & & Number isolated & Relative occurrence (\%) \\
\hline S. typhimurium & $14(6.1 \%)$ & 51.85 & & $03(2.1 \%)$ & 60.0 \\
S. newport & $06(2.6 \%)$ & 22.22 & & $02(1.4 \%)$ & 40.0 \\
S. gallinarum & $04(1.7 \%)$ & 14.81 & & - & - \\
S. enteritidis & $01(0.4 \%)$ & 3.70 & & - & - \\
S. infantis & $01(0.4 \%)$ & 3.70 & & - & - \\
S. worthington & $01(0.4 \%)$ & 3.70 & & - & - \\
Total & 27 & & & & \\
\hline
\end{tabular}

further incubated at $37{ }^{\circ} \mathrm{C}$ for $24 \mathrm{~h}$ for enrichment. Selective plating was performed using Hektoen enteric agar (HEA) (HiMedia, India) with overnight incubation at $37^{\circ} \mathrm{C}$. Typical black color colonies surrounded by narrow green margin on HEA were biochemically tested by Indole (I), Methyl Red (M), Vogus Proskeur (Vi), Citrate (C), Triple Sugar Iron (TSI) and Urease Test. The colonies showing Salmonella specific IMViC pattern $(-+-+)$ were inoculated on TSI slant. Furthermore, the colonies producing alkaline slant (pink) and acidic butt (yellow) with or without $\mathrm{H}_{2} \mathrm{~S}$ production (blackening) were tested for urease production on urea agar slant. All the urease negative isolates were considered as biochemically confirmed and were submitted to National Salmonella and Escherichia centre, Central Research Institute Kasauli, Himachal Pradesh, India for serotyping.

Optimization of PCR: APCR protocol was standardized targeting invA gene of Salmonella using vaccine strain E2375 of Salmonella typhimurium. A 26-bp forward primer (5'- GTG AAA TTA TCG CCG CGT TCG GGC AA3') and a 22-bp reverse primer (5' TCA TCG CAC CGT CAA AGG AAC C 3') [10] were used to obtain a 284 bp product. Amplification was carried out in a total volume of $25 \mu \mathrm{l}$ containing $10 \mathrm{pmols}$ of each primer, 50 $\mu \mathrm{M}$ of each dNTP, $1.5 \mathrm{mM} \mathrm{MgCl}_{2}, 1 \mathrm{U}$ Taq DNA polymerase, $1 \mathrm{X}$ PCR buffer and $5 \mu \mathrm{l}$ template DNA. Template DNA was prepared by boiling and snap chilling method [11]. A positive and negative control containing the template DNA from Salmonella typhimurium vaccine strain E2375 and nuclease free water, respectively, was included in every experiment. The reaction condition was optimized with initial denaturation at $94{ }^{\circ} \mathrm{C}$ for $5 \mathrm{~min}$ followed by 30 cycles of denaturation at $94{ }^{\circ} \mathrm{C}$ for $1 \mathrm{~min}$, annealing at $51{ }^{\circ} \mathrm{C}$ for $1 \mathrm{~min}$ and extension at $72{ }^{\circ} \mathrm{C}$ for $1 \mathrm{~min}$. Finally, an additional extension was achieved for $5 \mathrm{~min}$ at $72^{\circ} \mathrm{C}$. The PCR product was electrophoresed on a $1.5 \%$ agarose gel at $100 \mathrm{~V}$. The agarose gel was stained with ethidium bromide $\left(0.5 \mu \mathrm{g} \mathrm{ml}^{-1}\right)$ and visualized under gel documentation system (Biorad, USA).

Antimicrobial susceptibility test: The antibiotic susceptibility test of isolates was performed using agar disc diffusion method [12]. The antibiotic discs were impregnated with Ampicillin $(10 \mu \mathrm{g})$, Azithromycin $(15 \mu \mathrm{g})$, Amikacin $(30 \mu \mathrm{g})$, Clindamycin $(2 \mu \mathrm{g})$, Ceftri-

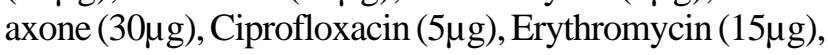
Gentamicin $(10 \mu \mathrm{g})$, Ofloxacin $(5 \mu \mathrm{g})$, Penicillin (10 units), Teicoplanin $(30 \mu \mathrm{g})$, Tetracycline $(30 \mu \mathrm{g})$ or Vancomycin $(30 \mu \mathrm{g})$ (HiMedia, India). The isolates were grown on autoclaved Mueller Hinton broths (HiMedia, India) for $18 \mathrm{hrs}$ at $37^{\circ} \mathrm{C}$. About $100 \mu \mathrm{l}$ of the inoculums was spread on Mueller Hinton agar using sterile disposable L shaped spreader and antibiotic discs were placed onto the plate using sterile forcep. The plates were incubated at $37^{\circ} \mathrm{C}$ for $24 \mathrm{hrs}$ and observed for zone of inhibition. The results were categorized as sensitive, moderately sensitive and resistant based on diameter of zone of growth inhibition corresponding to different isolates.

\section{Results and Discussion}

A total of 370 samples comprising of 228 raw chicken meat samples and 142 raw milk samples were processed for isolation and identification of Salmonella spp. by both growth enrichment on culture media and molecular techniques. Salmonella isolates were obtained from enriched samples by selective plating on HEA. Typical black colored colonies surrounded by narrow green margin were selected for biochemical characterization which showed the presence of Salmonella in 23.7\% (54/228) and 7.7\% (11/142) chicken meat and market milk samples, respectively. The serotyping of isolates showed the prevalence of Salmonella in 11.8\% (27/228) of chicken meat and 3.5\% (5/142) of market milk samples. Among different serotypes of Salmonella, S. typhimurium was detected in 6.1\% (14/228), S. newport in $2.6 \%$ (6/228), S. gallinarum in $1.7 \%$ (4/228), S. enteritidis, S. infantis and $S$. worthington in only $0.4 \%$ (1 each/228) of chicken meat samples, whereas, $2.1 \%$ (3/142) and 1.4\% (2/142) of $S$. typhimurium and $S$. newport, respectively were detected in market milk samples (Table-1). Our results are in agreement with the earlier findings reported from different geographic regions [13-17]. However, other investigators have reported 6.7 to $97.6 \%$ prevalence of Salmonella in chicken carcasses and milk $[5,18]$ which further substantiate the present finding. Many of these serotypes have been reported earlier in cultures from various sources and places. The relative occurrence (Table-1) of Salmonella serovars in the present study revealed the maximum prevalence for $S$. typhimurium (51.85\%) followed by S. newport (22.2\%), S. gallinarum (14.8\%), S. entritidis (3.7\%), S. infantis (3.7\%) and $S$. worthington (3.7\%) which is in accordance with previous finding $[4,18,19]$.

A PCR assay targeting invA gene of Salmonella 


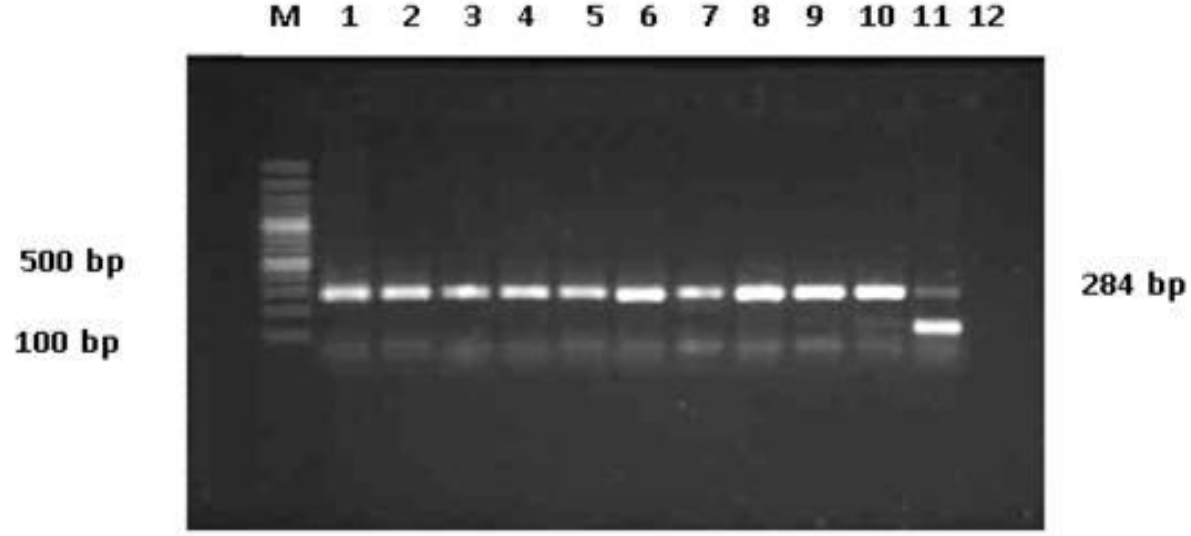

Figure-1. Electrophoresis of invA gene PCR products on $1.5 \%$ agarose.

Lane M : 100bp DNA ladder

Lane 1: Positive control

Lane 2-11: Samples isolates with positive amplicon

Lane 12: Negative control

was standardized for rapid detection and confirmation of Salmonella isolates. The assay relied on specific amplification of a $284 \mathrm{bp}$ product (Fig.1). All the biochemically confirmed isolates of Salmonella $(\mathrm{N}=65)$ were tested for amplification of invA gene by PCR. Among these, 76.92\% (50/65) showed specific amplification of invA gene of Salmonella, which comprises of $18.4 \%(42 / 228)$ and $5.6 \%(8 / 142)$ isolates from chicken meat and milk samples respectively which is a higher distribution than that showed by serotyping of isolates. The PCR assay also detected some of the isolates which had originally been detected as negative in serotyping study. This is in concordance with the finding of Hamza [20]. This may be attributed to the presence of rough mutant strains which lack the specific side chains responsible for ' $\mathrm{O}$ ' specificity or some additional abnormalities of the core structure [21] resulting in negative result in serotyping. Hence, the study recommends that PCR may be used for rapid and sensitive detection of Salmonella supported by the findings of Wang et al [7].

Since food of poultry origin and milk are some of the most common sources of human salmonellosis, the findings from this report may be correlated with the hygienic practices to reduce public health problem in the area of study.

The antibiotic susceptibility test of isolates revealed that all serotype were resistant to Gentamicin, Ampicillin, Penicillin, Erythromycin, Vancomycin, Amikacin and Clindamycin which are commonly used antibiotics. Most of the isolates were found to be highly sensitive to Azithromycin and Ceftriaxone and moderately sensitive to Ofloxacin, Ciprofloxacin and Tetracycline. The bacterium develops resistance to most of these commonly used antibiotics because of their inadvertent use for long duration or in suboptimal doses. Therefore, it is recommended to use antibiotics based on their antibiogram pattern only. Use of antibiotics based on earlier report of their effectiveness may not be effective at all times [13] because of the presence of resistant bacterium. The current study reveals that Salmonella isolates from chicken meat and milk are showing resistance to more than one antibiotic indicating the prevalence of multidrug resistant Salmonella, which substantiate the findings of Kumar et al., Siemon et al. and Kessel et al. [13, 18, 22].

\section{Conclusion}

The study concluded that non typhoidal Salmonella serotypes are prevailing in the poultry carcasses and milk and therefore act as a source of human infection. The level of prevalence can be reduced by adopting hygienic practices during poultry slaughter. The presence of multiple resistance in Salmonella isolates suggested that there is appreciable risk of infection to humans with multidrug resistant Salmonella from consumption of unpasteurized milk and undercooked chicken meat.

\section{Authors' contributions}

PK is a project leader and supervised the project. P K and Anjay carried out bacterial isolation and molecular characterization. SK, SKB and SD collected samples and carried out ABST. All authors contributed in drafting and revision of the manuscript. All authors read and approved the final manuscript.

\section{Acknowledgments}

The authors are grateful to The Vice Chancellor, Bihar Agricultural University, Sabour, Bhagalpur for financial support and Principal Bihar Veterinary College, Patna for extending full support while using facilities for the completion of work.

\section{Competing interests}

The authors declare that they have no competing interests.

\section{References}

1. Alcaine, S.D., Warnick, L.D. and Wiedmann, M. (2007) Antimicrobial resistance in nontyphoidal Salmonella. J Food Prot., 70: 780-790.

2. Fernandez, A.E., Calleja, A.C., Fernandez, G.C. and Capita, R. (2012) Prevalence and antimicrobial resistant of 
Salmonella serotypes isolated from poultry in Spain: comparison between 1993 and 2006. Int J Food Microbiol., 153:281-287.

3. El-Aziz, D.M.A. (2013) Detection of Salmonella Typhimurium in retail chicken meat and chicken giblets. Asian Pac. J. Trop. Biomed., 3: 678-681.

4. Vose, D., Koupeev, T. and Mintiens, K. (2013) Aquantitative microbiological risk assessment of Salmonella spp. in broiler (Gallus gallus) meat production. Technical report submitted to EFSA. 2010. Available at: http://www.efsa. europa. eu/en/ supporting/pub/183e.htm. Accessed on 01-12-2013.

5. Ramya, P., Madhavarao, T. and Rao, L.V. (2012) Study on the incidence of Salmonella Enteritidis in Poultry and meat Samples by Cultural and PCR Methods. Vet. World, 5: 541-545.

6. Tajbakhsh, M., Hendriksen, R.S., Nochi, Z., Zali, M.R., Aarestrup, F.M. and Garcia-Migura, L. (2012) Antimicrobial resistance in Salmonella spp. recovered from patients admitted to six different hospitals in Tehran, Iran from 2007 to 2008. Folia Microbioloca., 57:91-97.

7. Li, R., Wang, Y., Shen, J. and Wu, C. (2013) Development of a novel hexa-plex PCR method for identification and serotyping of Salmonella species. Foodborne Patho. Dis., 11:75-77.

8. Malorny, B., Bunge, C. and Helmuth, R. (2003) Discrimination of D-tartrate-fermenting and non fermenting Salmonella enteric subspp. Enteric isolates by genotypic and phenotypic methods. J. Clin. Microbiol., 41: 4292-4297.

9. Angulo, F.J., Nargund, V.N. and Chiller, T.C. (2004) Evidence of an association between use of anti-microbial agents in food animals and anti-microbial resistance among bacteria isolated from humans and the human health consequences of such resistance. J. Vet. Med. B Infect. Dis. Vet. Public Health, 51: 374-379.

10. Rahn, K.S., De Geandis, S.A., Clarke, R.C., Curtiss, R. and Gyles, C.L. (1992) Amplification of invA gene sequence of Salmonella Typhimurium by polymerase chain reaction as a specific method of detection of Salmonella. Mol. Cell. Probes, 6: 271-279.

11. Nagappa, K., Tamuly, S., Brajmadhuri, Saxena, M.K. and Singh, S.P. (2007) Isolation of Salmonella Typhimurium from poultry eggs and meat of tarai region of Uttranchal. Indian J. Biotech., 6: 407-409.

12. Wayne, P.A. (2002) Performance standards of antimicrobial susceptibility. National Committee for Clinical Laboratory Standards (NCCLS). NCCLS approved standards. pp. M 100-M 159.

13. Kumar, T., Mahajan, N.K. and Rakha, N.K. (2012) Isolation and prevalence of Salmonella serovars from poultry in different parts of Haryana, India. Indian J. Anim. Sci., 82: 557-560.

14. Akbarmehr, J. (2010) Isolation of Salmonella species from poultry (ostrich, pigeon and chicken) and detection of their hilA gene by PCR method. Afr. J. Microbiol. Res., 4: 26782681. http://www.academicjournals.org/ajmr. Accessed on 17-08-2013.

15. Surendran, D., Agarwal, R.K. and Bhilegaonkar, K.N. (2003) PCR based detection of Salmonella from meats. $J$. Vet. Publ. Health, 1: 113-124.

16. Karshima, N.S., Pam, V.A., Bata, S.I., Dung, P.A. and Paman, N.D. (2013) Isolation of Salmonella species from milk and locally processed milk products traded for human consumption and associated risk factors in Kanam, Plateau State, Nigeria. J.Anim. Prod. Adv., 3: 69-74.

17. Minj, A.K. and Behera, N. (2012) A comparative microbiological quality assessment of rural and urban milk samples. Afr. J. Food. Sci., 6: 519-523.

18. Kessel, V., Sonnier, J., Zhao, S. and Kams, J.S. (2013) Antimicrobial resistance of Salmonella enterica isolates from bulk tank milk and milk filters in United States. J. Food Prot., 76: 18-25.

19. Tony, M.F., Scott, N., Marika, M., Roney, C.S., Thomas, M.G., Jennifer, R.M., Nguyen, T. and Behravesh, C.B. (2012) Notes from the Field: Multistate Outbreak of Salmonella Infantis, Newport, and Lille Infections Linked to Live Poultry from a Single Mail-Order Hatchery in Ohio. Report from CDC. 404-639-1334.

20. Eid, H.M.I. (2010) Rapid Detection of Salmonella in dairy cows using polymerase chain reaction. J. Am. Sci., 6:31-37.

21. Topley and Wilson's. (1990) Principles of bacteriology, virology and immunity. In: Parker M T and Brian I (ed) Systematic bacteriology $8^{\text {th }}$ edn, Edward Arnold, Hodder And Stoughton Publishers, London, pp. 475-450.

22. Siemon, C.E., Bahnson, P.B. and Gebreyes, W.A. (2007) Comparative investigation of prevalence and antimicrobial resistance of Salmonella between pasture and conventionally reared poultry. Avian Dis., 51:112-117.

$* * * * * * * *$ 